\title{
Gendered Wealth Losses after Dissolution of Cohabitation but not Marriage in Germany
}

\author{
Diederik Boertien ${ }^{1}$ \& Philipp M. Lersch ${ }^{2}$
}

Objective: To document gender differences in how economic wealth changes following the dissolution of marriage and cohabitation in Germany.

Background: Wealth can be an important resource to deal with the adverse economic consequences of union dissolution. Marital property regimes usually ensure that both partners receive a share of the couples' wealth following a divorce. The dissolution of cohabiting unions is not governed by such rules in most countries, including Germany, which may lead to a more unequal division of wealth following the dissolution of cohabitation as compared to marriage.

Method: The analysis consists of multivariable fixed-effects regression models based on longitudinal data from the German Socio-Economic Panel ( $N=6,388$ individuals) for the years 2002 to 2017 .

Results: Changes in wealth are relatively similar for men and women after the dissolution of marriage. The dissolution of cohabiting unions is related to losses in wealth for women, but not for men. Controlling for post-dissolution processes, gender inequality increases after the dissolution of cohabitations.

Conclusion: Union dissolution is associated with wealth losses. The legal protection of the economically weaker spouse in marriage prevents gender inequality in these wealth losses. Lacking such legal protection, cohabitation is associated with gender inequality in the consequences of dissolution.

\footnotetext{
${ }^{1}$ Center for Demographic Studies, dboertien@ced.uab.es

${ }^{2}$ Humboldt-Universität zu Berlin \& DIW Berlin, p.m.lersch@hu-berlin.de
} 
Acknowledgement: Diederik Boertien acknowledges funding from the Beatriu de Pinos program of the Generalitat de Catalunya (2016-BP-00121), the EQUALIZE project (ERC2014-STG-grant agreement No 637768), and the GLOBFAM project (RTI2018-096730-BI00). Philipp M. Lersch's research was funded by the Support Network for Interdisciplinary Social Policy Research (FIS) of the German Federal Ministry of Labor and Social Affairs and by the German Research Foundation (DFG), grant number LE 3612/2-1. 
How consequential are union dissolutions for individuals' economic resources and their financial wellbeing? A large body of literature has documented how household income drops after union dissolution (Andreß et al. 2006; McManus \& DiPrete, 2001; Smock, 1994; Uunk, 2004; Van Damme et al., 2008). Given that these economic consequences are greater for women (Andreß et al. 2006; DiPrete \& McManus, 2000; Van Damme et al., 2008), union dissolution has become a factor that contributes to gender inequality in economic resources. What is missing from this relatively large body of literature on the economic consequences of union dissolution is what happens with men's and women's wealth after a union dissolution (exceptions are Addo \& Lichter, 2013; Painter et al., 2015; Wilmoth \& Koso, 2002; Zagorsky, 2005).

It is important to include wealth in the study of the economic consequences of union dissolution for several reasons. First, union dissolution is a potential driver behind wealth inequality between individuals (Zagorsky, 2005). Secondly, accumulated wealth can be employed to cushion the impact of a separation on a person's standard of living (Killewald et al., 2017). How well men and women are able to deal with a union dissolution is dependent on initial levels of household wealth, how wealth is split between partners, and differences in individual wealth accumulation following a break-up. Even though income differences following union dissolution predominantly favor men, (parts of) wealth is in principle split equally among partners following a legal divorce (depending on the legal context). In some legal contexts, women might claim larger parts of household wealth due to their higher financial need following dissolution (Smith, 2002). If this is the case, wealth can turn out to be an important resource cushioning gender differences in the overall economic consequences of union dissolution. 
At the same time, there are several reasons to believe that wealth trajectories of expartners might diverge following union dissolution. First of all, the division of wealth following a divorce will be influenced by the marital property regime of the context studied. In Germany, the country-case of our study, the default property regime stipulates equal sharing of wealth accrued during marriage. There are important exceptions to this default regime: Pre-marriage wealth and inheritances are not shared and through prenuptial agreements the default property regime may be modified. Given that women are likely to bring less wealth into the marriage (Sierminska et al., 2010) we expect them to leave a relationship with less wealth, too.

Secondly, the separation of cohabiting unions is not governed by the same rules as marriage (Perelli-Harris \& Sánchez Gassen, 2012). Even though wealth accumulated during marriage is normally split equally between partners, this is not necessarily the case for wealth accumulated during cohabitation. Given the higher earnings of men as compared to women, men are likely to generate more (financial) wealth during relationships as compared to women (Lersch, 2017). After the dissolution of a marriage, women normally have the right to half of this accumulated wealth, but within cohabitation women might not be able to claim such a share. The dissolution of cohabiting unions might therefore have more gender unequal consequences as compared to the dissolution of marriages.

In short, there are important reasons to expect that only examining income underestimates gender inequality in the economic consequences of union dissolution. The division of wealth may amplify rather than dampen the gendered consequences of union dissolution. In this study, we use longitudinal data from the German Socio-Economic Panel (SOEP) to document changes in wealth of individuals before and after union dissolution. The main questions we ask are: Do changes in per capita wealth differ between men and 
women after union dissolution? Do these gender differences vary between the dissolution of cohabitation and marriage?

Our results indicate that both men and women end up with less wealth after dissolution of marriage and changes in wealth are relatively similar for men and women. At the same time, we find that the dissolution of cohabiting unions is related to wealth losses for women (6.5 percentage points in the per capita wealth rank), but not for men. If future research confirms and consolidates this finding, and if cohabitation becomes more prevalent compared to marriage, union dissolution might become an increasingly important determinant of gender differences in wealth.

\section{BACKGROUND}

\section{Gender, Union Dissolution, and Wealth}

A handful of studies have documented how union dissolution relates to wealth in the United States (Addo \& Lichter, 2013; Halpern-Manners et al., 2015; Painter et al., 2015; Wilmoth \& Koso, 2002; Zagorsky, 2005). These studies have generally examined household wealth of individuals at a given point in time depending on partnership trajectories experienced in the past (with the exception of the analysis of changes over time performed by Zagorsky [2005]). Individuals who experienced a union dissolution are found to have lower household wealth compared to continuously partnered people (Addo \& Lichter, 2013; Painter et al., 2015; Wilmoth \& Koso, 2002; Zagorsky, 2005). Findings regarding re-marriage have been mixed. Some studies found re-marriage to dampen or eliminate the effects of union dissolution (Painter et al., 2015; Wilmoth \& Koso, 2002), but other studies found persisting disadvantage after re-marriage (Addo \& Lichter, 2013). 
Several mechanisms have been suggested to underlie this empirical regularity. Firstly, economies of scale make it cheaper for two individuals to live together instead of having to maintain two separate households. Union dissolution implies losses of these economies of scale. In addition, at least one partner must find new accommodation. The costs related to such a move are likely to reduce the overall stock of wealth of the two former partners (Zagorsky, 2005). Secondly, direct costs of legal divorce may reduce wealth after marriage. Thirdly, besides economies of scale there are other reasons why persons in a union accumulate more wealth as compared to single individuals; these include possible tax benefits and increased incentives to save (Lersch, 2017; Vespa \& Painter, 2011). Union dissolution will put an end to such benefits related to being in a union. Fourthly, behavior changes following separation (Zagorsky, 2005) and these changes might affect earnings, consumption, and saving. In particular, many women who end up with custody of dependent children might have to reduce their labor supply following a break-up (Van Damme et al., 2008). Lastly, individuals who end a union might be selected in terms of their economic resources as compared to individuals who stay with their partner. The cross-sectional differences in wealth observed in some of the previous studies (Addo \& Lichter, 2013; Wilmoth \& Koso, 2002) might therefore reflect pre-existing economic disadvantage rather than a causal effect of union dissolution.

Two previous studies looked at gender differences in the effects of marital histories on wealth and found mixed results. Zagorsky (2005) found women's wealth to be slightly more affected, but concluded that divorce "destroys wealth dramatically for both sexes" (p. 418). Wilmoth and Koso (2002) did not find significant gender differences in the effects of separation from first marriages, but found such differences for separation from higher order 
marriages and for divorce (regardless of union order). No study has examined changes in wealth after the dissolution of cohabitation.

In short, existing research has paid little attention to the question whether there are gender differences in the consequences of union dissolution for wealth. Why might we expect such gender differences to exist? We propose three general reasons that will be discussed in turn: rules specific to marital property regimes, wealth accumulation within cohabitation, and gender differences in post-separation processes. In our study, we focus on the first two processes and our substantive interest is in understanding the role of predissolution characteristics of unions for the post-dissolution wealth of both ex-partners.

\section{Marital Property Regimes}

Divorce marks the legal end of marriage where the final re-distribution of wealth is settled according to marital property regimes. We expect that partners anticipate these legal obligations and, therefore, that the consequences of dissolution of marriage already emerge with the end of co-residence of both partners when they divide their property.

The extent to which wealth is shared after a divorce depends on the legal context studied. What parts of wealth are divided after divorce and what the leading principle is to achieve an equitable distribution of assets differs across countries. In some countries, such as England and Wales, "need" is the leading principle to determine the distribution of all property and judges have great discretion in dividing assets (Smith, 2002). Given that needs vary across individuals such a system might lead to an unequal division of wealth after divorce. Given that children often co-reside with the mother after a divorce and because women in general earn less, their financial need is on average higher after dissolution 
compared to men. Systems that take into account financial need might therefore end up giving relatively more wealth to women as compared to other systems.

In other countries, wealth is in principle divided equally across former partners, which might lead partners with more financial needs to end up in an economically more difficult position. In some countries, such as the Nordic countries, all wealth is divided equally across partners, whereas in others only wealth accumulated during the marriage is split, such as in Germany (Smith, 2002) the country of our study. Men in general accumulate more (financial) wealth within marriage, and bring more wealth to the marriage, possibly due to their age and status differences at union formation (Lersch, 2017). Hence, the more wealth is covered by marital property regimes, the smaller the gender gap in wealth is likely to be following divorce.

In the United States, property regimes differ across states, but in general take into account need, and in several states all wealth of the couple is divided, including wealth accumulated before marriages (Voena, 2015). Most divorce cases end up in an equal division of wealth in the United States (Zagorsky, 2005). But, the relatively weak evidence for the existence of a gender gap in wealth following divorce - all based on the United States - might not generalize to other contexts that have different marital property regimes in place.

Finally, rising divorce rates might make couples more wary of entering into a union that leads to a possible high loss in wealth in the case of divorce. Prenuptial agreements might therefore have become more relevant (Rainer, 2007) and might have led to a less equal division of wealth following divorces today. At least for France, evidence indeed showed that married couples increasingly sign prenuptial agreements and separate their 
wealth (Frémeaux \& Leturcq, 2018). For Germany, these trends have not yet been examined.

\section{Wealth Accumulation within Cohabitation}

If the law makes the distribution of wealth after divorce relatively equal, the division of wealth might be less equal after the dissolution of cohabiting unions, which are not governed by the same legal rules. In that case, increasing levels of cohabitation might give rise to a gender gap in how household wealth is divided following union dissolution.

Countries differ in the extent to which cohabitation is legally regulated. Cohabiting couples normally do not have to inform authorities about the dissolution of their union, and if so, procedures are relatively simple (Perelli-Harris \& Sánchez Gassen, 2012). Some countries mention cohabiting unions in their laws, but the dissolution of cohabiting relationships remains largely unregulated, with the partial exceptions of Sweden, Norway, and registered partnerships in France and the Netherlands. In Germany, the country case of our study, the dissolution of cohabiting unions is not governed by laws with the exception of alimony payments if the couple recently had a child (Perelli-Harris \& Sánchez Gassen, 2012:448). The division of wealth after union dissolution will therefore primarily depend on the couple's decisions and the legal ownership of assets and debts.

The higher earnings potential of men is likely to lead to an unequal accumulation of wealth within relationships (Lersch, 2017). In most countries and cases such wealth is split within marriage, but this is not the case for wealth accumulated within cohabitation. Gender differences in how wealth is split are therefore, ceterus paribus, likely to be more pronounced after the dissolution of cohabitation as compared to divorce. Similarly, men bring more wealth to relationships (Sierminska et al., 2010). Especially in countries where pre-marriage wealth is divided between partners after divorce but not after the dissolution of 
a cohabiting union, the gender gap in wealth losses after the dissolution of cohabitation as compared to divorce might therefore be stark.

\section{Post-dissolution Processes}

Direct information on how wealth is split between partners will not be available in most empirical settings. Instead, wealth is normally measured at a given point in time before and after the event (e.g. Zagorsky, 2005). Estimates of how wealth is split will therefore rely on estimating the distinct changes in wealth for both partners after union dissolution. In such settings, gender differences in wealth will be influenced by post-dissolution processes. Two such processes appear important to highlight: variation in earnings, consumption, and savings on the one hand, and re-partnering on the other hand.

Given the greater economic consequences of union dissolution for women in terms of household income, and the greater economic need of women living with children (Andreß et al. 2006; McManus \& DiPrete, 2001; Smock, 1994; Uunk, 2004; Van Damme et al., 2008), separated women are likely to consume more and save less as compared to separated men. This will result in gender differences in wealth trajectories following union dissolution favoring men.

Studies on the changes in wealth following divorce have generally found repartnering to offset part of its negative effects of union dissolution on women's wealth (Painter et al., 2015; Wilmoth \& Koso, 2002). However, given that men in general re-partner more often and faster (Di Nallo, 2019), re-partnering might actually increase the average gap in wealth between men and women following union dissolution. 


\section{This Study: Union Dissolution and Wealth in Germany}

In this article, we study union dissolution in $21^{\text {st }}$ century Germany. We follow individuals across time in order to estimate changes in per capita wealth after union dissolution. Given our interest in how all household wealth is split after a couple breaks up, per capita wealth is more appropriate for our purposes as compared to measures of individual wealth (i.e. based on the legal ownership of wealth).

Previous studies have found some gender differences in wealth following divorce in the United States (Wilmoth \& Koso, 2002; Zagorsky, 2005). We expect to find clearer gender differences in our study for two reasons: (a) In Germany, important parts of wealth are not divided after divorce (i.e. pre-marriage wealth), whereas this is not the case in all states of the United States; (b) we include cohabiting unions where no division of wealth is required after dissolution. If men indeed bring more wealth into unions and accumulate more wealth within unions in general, which appears to be the case (Lersch, 2017), women should end up with less wealth after union dissolution as compared to men in Germany.

Besides estimating the overall change in per capita wealth after union dissolution, a second major goal of this article is to test the argument whether wealth is split less evenly after cohabitation as compared to marriage.

Differences between cohabitation and marriage have not been studied longitudinally in previous research. In Germany, differences between cohabitation and marriage are likely to be smaller as compared to countries where pre-marriage wealth is divided after divorce. At the same time, differences between cohabitation and marriage can be expected to be larger in Germany than in contexts which legally regulate cohabitation. 


\section{DATA \& METHOD}

\section{Data}

We use longitudinal data from the Socio-economic Panel (SOEP; version 34; doi: 10.5684/soep.v34) covering the period 2002-2017. The SOEP is a panel survey interviewing a representative sample of the German population on an annual basis. Information on wealth has been collected by the SOEP every five years since 2002. In the current study, we therefore use information on wealth from four measurement points $(2002,2007,2012,2017)$ and waves in between are used for additional variables.

\section{Sample}

We construct two samples for the analysis selecting all respondents who were either in (a) a co-residential relationship or (b) married during any of the four waves with information on wealth. We follow them from the first wave they are in a union until the end of the observation period. Respondents that marry their cohabiting partner are censored in the cohabitation sample and enter the marriage sample. We restrict the sample to respondents aged 18 to 79 , to private households, and to household heads and their partners. We exclude same-sex couples and extension samples without wealth measurement. We subsequently construct a person-year dataset with information from all waves for which individuals provided information on wealth. This setup allows us to examine differences in predissolution and post-dissolution wealth.

We draw on multiply imputed wealth data from the SOEP team. Additionally, around $1 \%$ of the sample contains missing information on the dissolution and control variables. We multiply impute 40 possible values for missing information and use the resulting 40 imputed datasets in the analysis. This results in a final sample of 836 individuals who cohabited during the observation window and a sample size of 5,552 for our analysis of marriage 
dissolution. Table 1 shows the number of persons included in the final sample and separation events for men, women, married and cohabiting individuals used in the final analysis.

Table 1. Sample Sizes and Number of Events Recorded

\begin{tabular}{lcc}
\hline & Women & Men \\
\hline Cohabiting persons & 428 & 408 \\
Number of dissolutions from cohabitation & 209 & 183 \\
Married persons & 2,871 & 2,681 \\
Number of dissolutions from marriage & 302 & 197 \\
\hline
\end{tabular}

\section{Measurement}

Wealth. The outcome of interest is total net wealth (all assets minus debts and loans). Assets include real estate, financial assets, life insurance, private pension plans, businesses and debts include mortgages, loans, and other debts. The SOEP collects wealth at the individual level. When collecting data on collectively owned assets and debts, each individual is asked how ownership of this asset is shared between household members. We focus on per capita wealth, which is operationalized as total household net wealth divided by the number of household members aged 18 or above. Wealth is adjusted for price inflation (set to prices of 2015) and its distribution is winsorized at the 0.1 and 99.9 percentiles.

Wealth is a highly skewed variable, but given that wealth has both positive and negative values, commonly used transformations (such as the natural logarithm) would exclude important information from the analysis. The two most common ways to transform wealth are to calculate a rank measure or to employ the Inverse Hyperbolic Sine (IHS)transformation (Killewald et al., 2017). In our case, the advantage of using a rank-based 
measure is that it more effectively accounts for periodic changes in the distribution of wealth (and hence effect sizes) and provides easy to interpret results. In the main analysis, we therefore use individuals' rank in the wealth distribution as the dependent variable. This rank is calculated for each wave separately jointly for men and women and indicates the proportion of cases having less wealth than the individual considered and ranges from 0 to 1 . In robustness checks, we use the IHS-transformed version of the per capita wealth variable with a theta of 0.0001 (Friedline et al., 2015).

Union Dissolution. We define union dissolution similarly for cohabitation and marriage: an individuals' partner who was observed in the household in a given wave is not in the household anymore in the next wave with information on wealth and the partner has not died. We do not consider cases as dissolution if partners are again observed in the same household in later waves. For individuals who experienced the dissolution of a union, this variable takes on the value 1 for all waves following dissolution. Thus, after marriage we do not differentiate between end of co-residence and divorce in the main analysis, but provide robustness checks focusing on divorce. Person-years before dissolution take on the value of 0 , and this counts for all the person-years of individuals who did not experience a dissolution between 2002 and 2017, too.

In our analysis, we compare changes in wealth following the dissolution of cohabiting unions to changes after the dissolution from marriage. For these comparisons, we estimate results separately for a subsample of marriages and a subsample of cohabiting unions. In additional analysis, we also consider the variable Time since dissolution which captures the waves elapsed since the partner was not observed in the same household anymore and Union duration before dissolution. 
Additional variables. We control for survey year, age, and age squared in all models. Given that our main interest is in how wealth is split following union dissolution rather than how other post-dissolution processes affect wealth, we also account for several variables that capture such post-dissolution processes in part of the analysis. These variables include: logged household income, the number of children below 18 in the household (categorical), self-rated health, and dummy variables indicating being employed, the presence of a child below the age of 10, whether the respondent lives at the same address as in the last wave, and whether the respondent has a new partner.

\section{Analytical strategy}

First, we present mean wealth by partnership status separately for women and men.

Descriptive results are weighted with the cross-sectional household weights provided in the SOEP. Second, we estimate individual fixed-effects models to estimate differences in wealth before and after union dissolution:

$$
Y_{i t}=D_{i t} \gamma+X_{i t} \beta+\alpha_{i}+v_{i t}
$$

where $Y_{i t}$ is per capita wealth of individual $\mathrm{i}$ in year t. $D_{i t}$ is a time-varying indicator of whether the individual experienced union dissolution after 2002 but before $t$. X is a vector of control variables, $\alpha_{i}$ is the unobserved time-invariant individual component, and $v_{i t}$ is an error term. This specific setup allows us to estimate differences between pre- and postdissolution wealth for individuals who separated.

It is important to note that the goal of our analysis is not to identify the causal effect of dissolution on wealth. This identification is, for instance, hampered by other time-varying characteristics that can determine how much wealth changes from wave to wave. Instead, 
our primary goal is to descriptively examine how wealth is split after dissolution among the separated. For all analyses, we adjust standard errors for clustering within individuals.

\section{RESULTS}

\section{Descriptive results}

Figure 1 shows the average wealth of individuals according to union status and gender. Married individuals and men who separated from marriage have most wealth. Because of our measurement of wealth as per capita, women and men should have equal wealth in unions, but small differences emerged because we did not observe both partners for all couples.

Figure 1. Average Per Capita Wealth By Union Status.

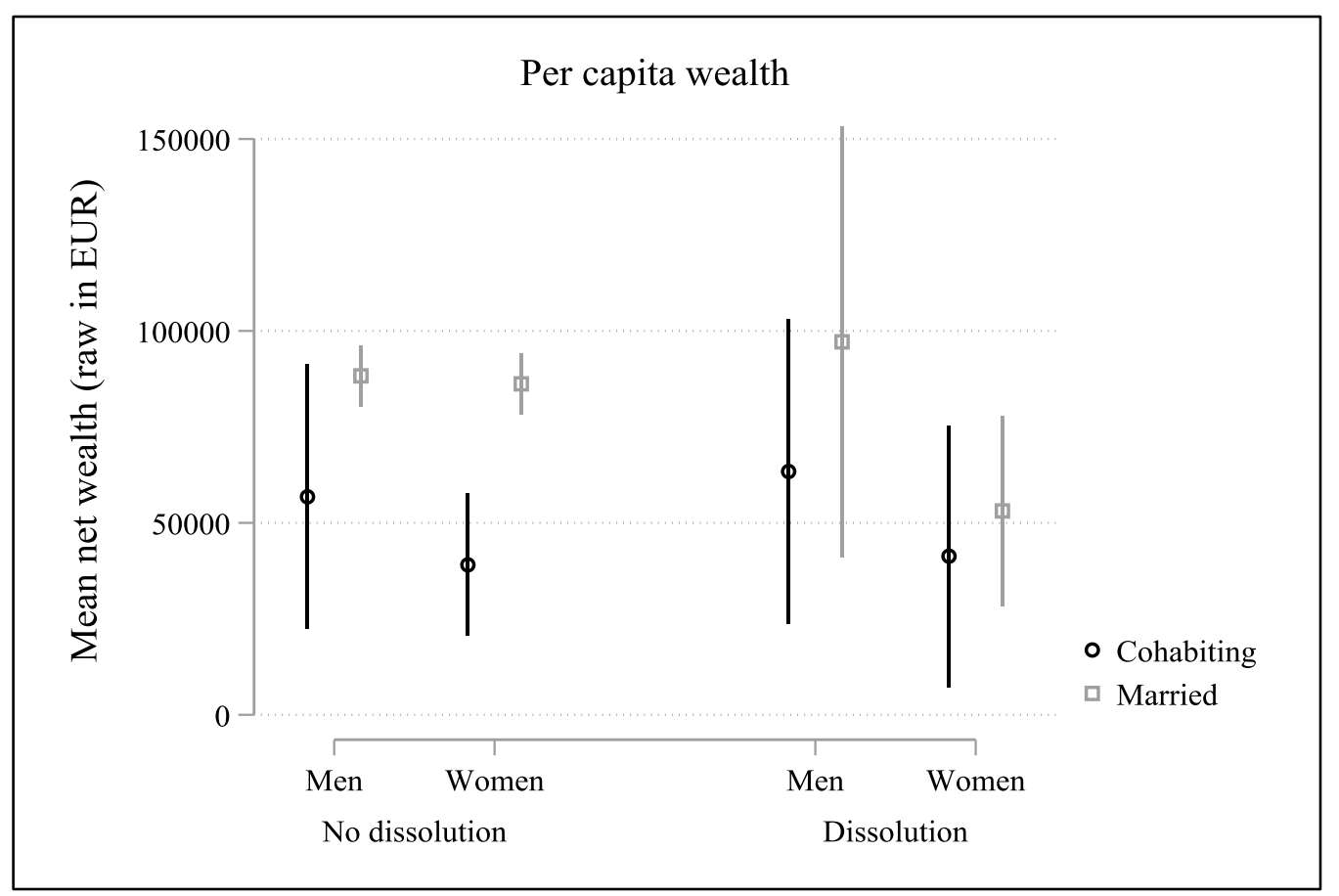

Note: Dissolution is separation from cohabiting union or marriage since first wave of observation but before year of measurement. Marital status indicates status when union dissolved. Bars indicate 95\% confidence intervals. 
Among those who separated, women have lower wealth than men. Gender differences exist among both formerly cohabiting and formerly married couples. These results would suggest that the splitting of wealth is gender unequal following the dissolution of both cohabiting unions and marriages. However, these numbers do not account for initial levels of wealth, are not yet transformed to wealth ranks, and are not adjusted for necessary controls. We therefore turned to multivariable results explaining variation in the wealth rank among individuals across time, which are discussed in the next section.

\section{Multivariable results}

Figure 2 shows the main results of our individual-level fixed effects models. For each of the four groups (defined by gender and marital status) we estimated a separate model and plotted the coefficient for having experienced a union dissolution. The figure shows that dissolution from marriage has a negative and statistically significant effect on wealth. Individuals who separated from marriage have a per capital wealth ranking that is around 8 to 9 percentage points lower. The consequences of dissolution after marriage are similar for

men and women. Even though the standard marital property regime in Germany only covers wealth accumulated during marriage, this does not seem to translate in a gender unequal division of wealth following the dissolution of marriage, on average.

Results differ for the dissolution of cohabiting unions. Women experience average drops in wealth that are similar to those experienced by women who leave a marriage, but the effect is slightly smaller and statistically insignificant here given the very wide confidence interval due to the small sample of cohabiting individuals. Men's wealth appears to be unaffected by leaving a cohabiting union as the effect size is virtually 0 . This result is in line with our expectation that the lack of legal protection regarding the splitting of wealth 
in the case of ending a cohabiting union might lead to a more gender unequal division of wealth. Note, however, that the coefficients for women and men are not statistically significantly different from each other.

FIGURE 2. EFFECT OF SEPARATION ON PER CAPITA WEALTH RANK BY UNION STATUS AND GENDER.

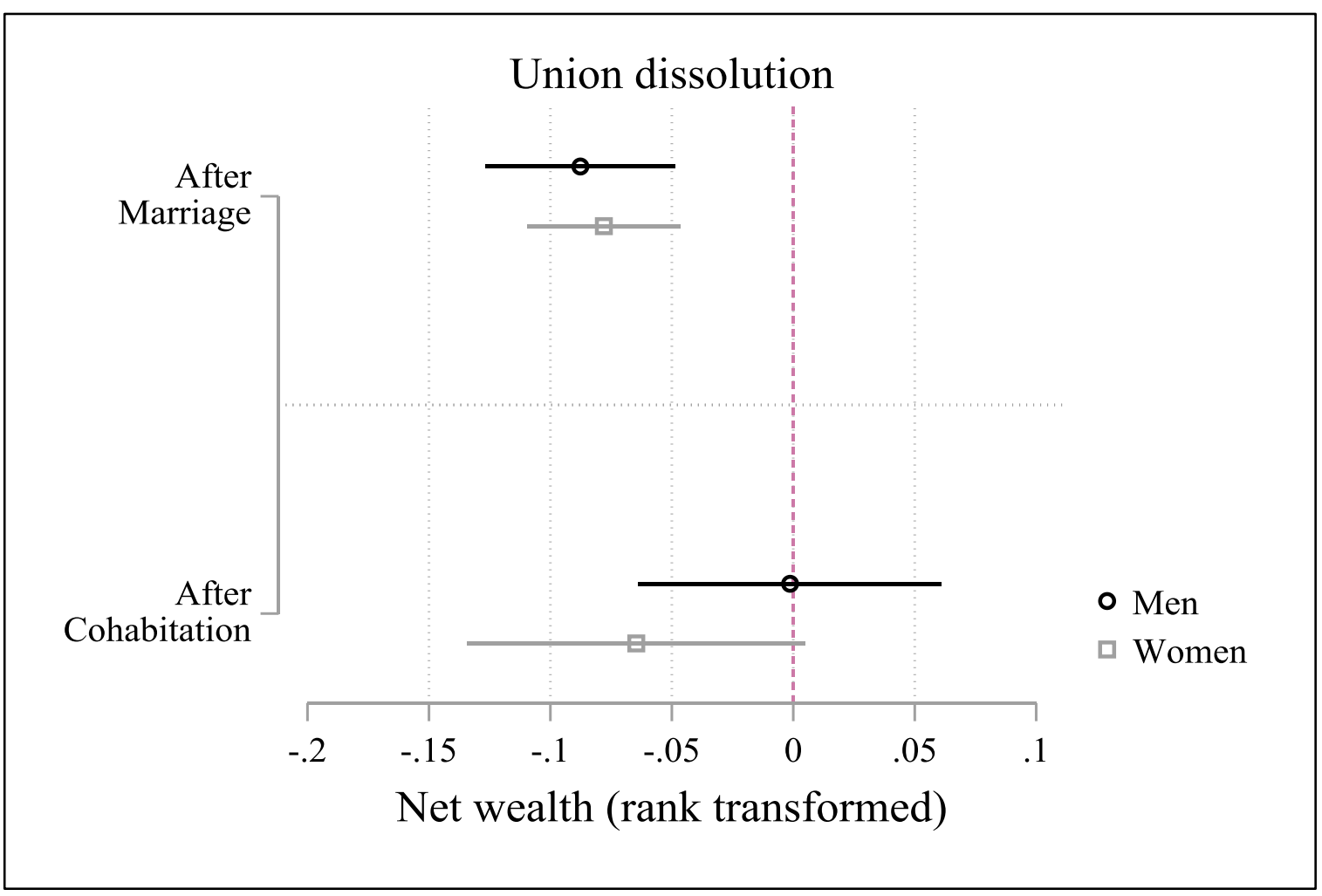

Note: Coefficients from individual fixed-effects models indicating difference between pre-separation and post-separation wealth. Separate models ran by union status and gender. Bars indicate $95 \%$ confidence intervals.

It has to be emphasized that we did not directly measure how wealth is split between partners following union dissolution. It could therefore well be that results are driven by post-dissolution processes including gendered income changes and custody arrangements following a union dissolution. Figure 3 therefore reproduces our main result, but controls for variables that should capture such post-dissolution processes: employment, presence of 
(young) children in the household, re-partnering, having moved homes, log household income, and self-rated health. Accounting for these variables led to slightly larger estimated wealth losses for women, and slightly lower losses for men. In this specification, the wealth losses for women following the dissolution of a cohabiting union turn statistically significant (but note that the difference in wealth losses between men and women following the dissolution of a cohabiting union remains statistically insignificant). That gender differences persisted suggests that it is mainly the division of wealth following union dissolution that drives results and not the other post-dissolution processes considered in our analysis.

FIGURE 3. EFFECT OF SEPARATION ON PER CAPITA WEALTH RANK BY UNION STATUS AND GENDER; CONTROLLING FOR VARIABLES CAPTURING ECONOMIC NEED

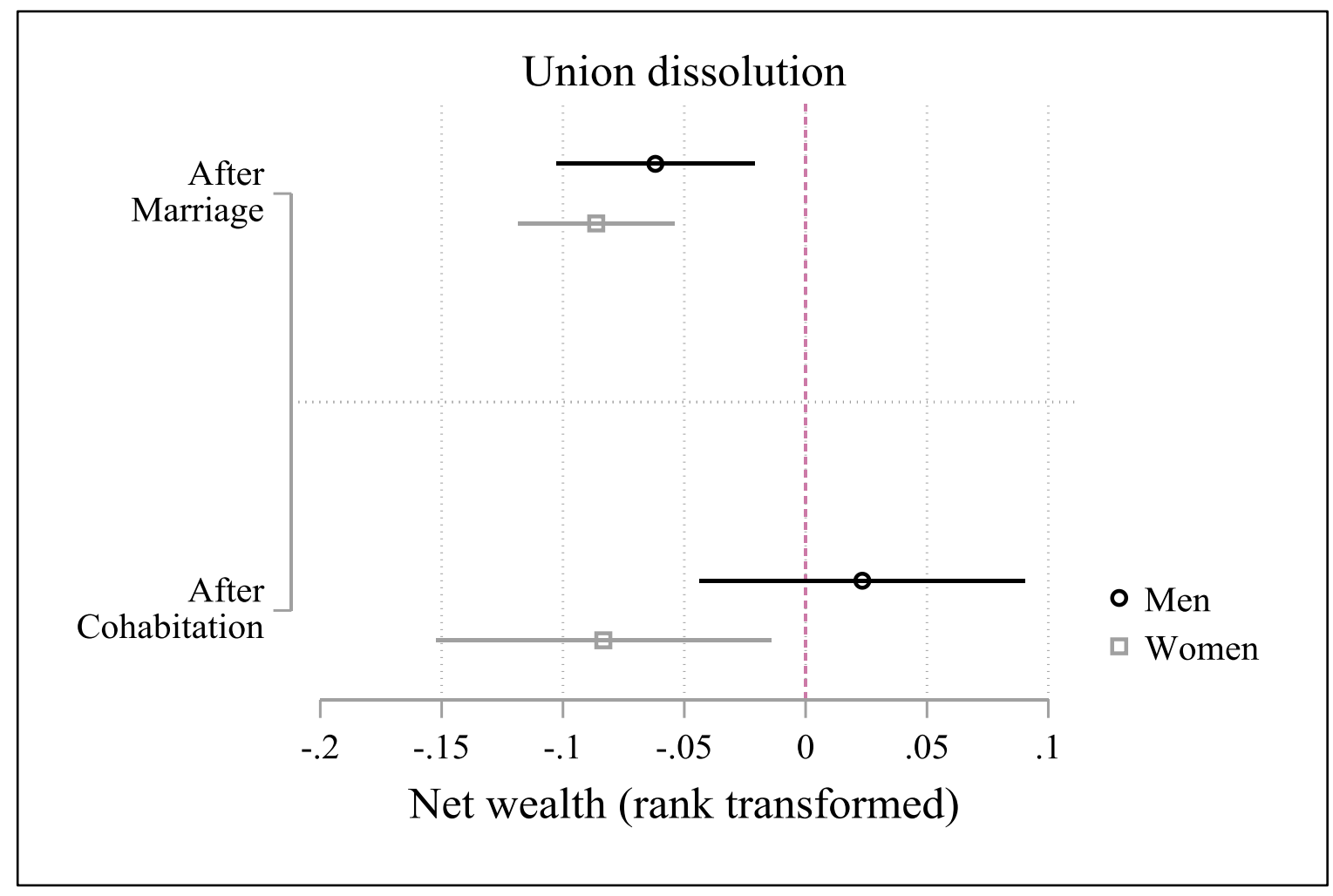

Note: Coefficients from individual fixed-effects models indicating difference between pre-separation and post-separation wealth. Separate models ran by union status and gender. Controlled for employment, presence of (young) children in the household, re-partnering, having moved homes, log household income and self-rated health. Bars indicate 95\% confidence intervals. 
Finally, we examined two major components of wealth separately: housing and financial wealth. Figure 4 shows the results of this analysis without controlling for postdissolution processes (i.e., the equivalent of Figure 2). For married men and women, losses are the largest in terms of housing wealth following dissolution. For cohabiting couples, wealth losses are slightly large for individuals' financial wealth rank than for housing wealth rank. Gender differences are also slightly larger for financial wealth than for housing wealth following the separation from cohabiting unions.

FIGURE 4. EFFECT OF SEPARATION ON HOUSING AND FINANCIAL WEALTH RANK BY UNION STATUS AND GENDER

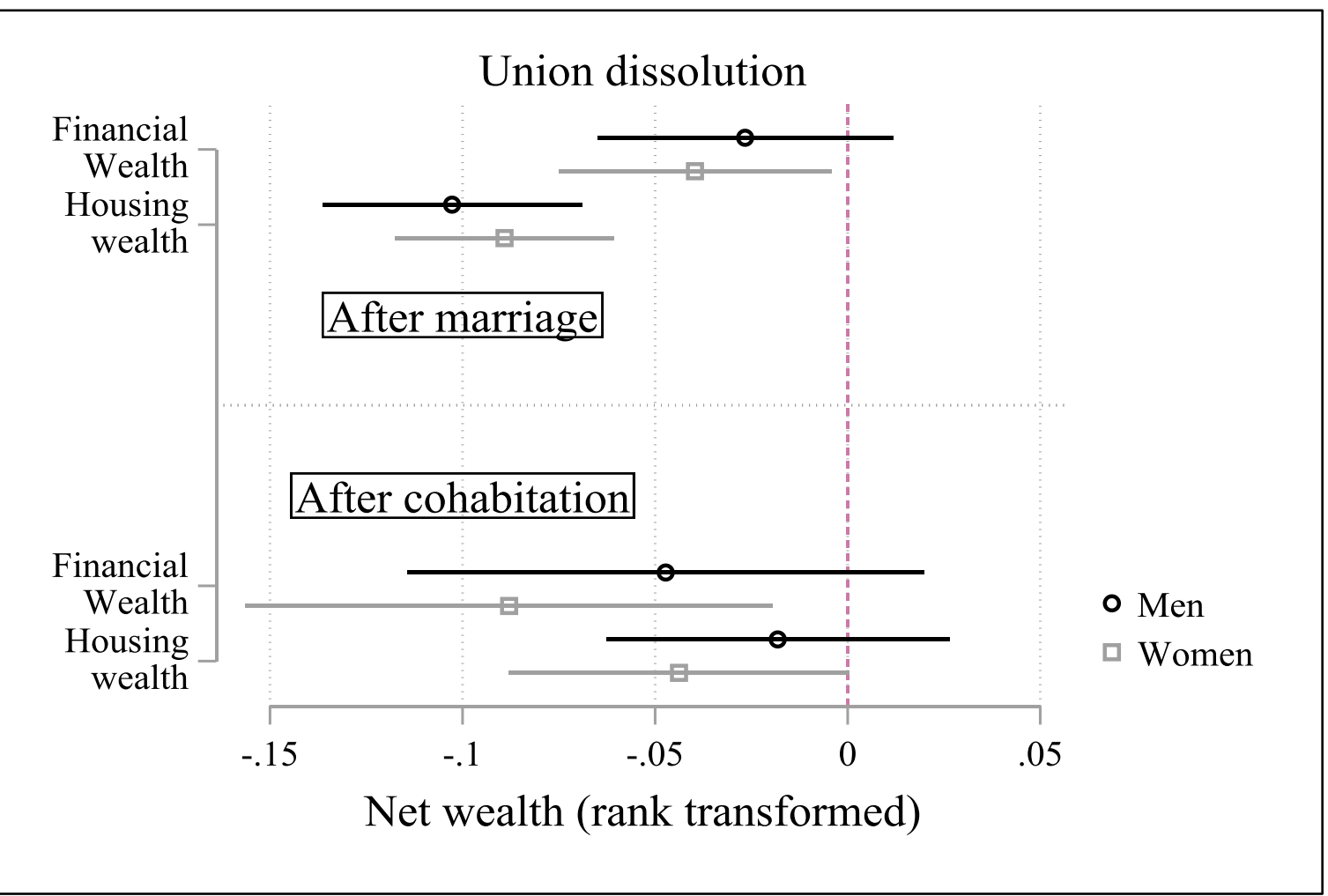

Note: Coefficients from individual fixed-effects models indicating difference between pre-separation and post-separation wealth. Separate models ran by union status and gender. Bars indicate $95 \%$ confidence intervals. 


\section{Robustness checks}

We ran various additional models for a better understanding of our main results and to test the robustness of our results. Firstly, results were robust to using IHS-transformed wealth instead of wealth ranks (Online Appendix A), and restricting the analysis to legal divorces rather than dissolutions from marriage in general (Appendix B). Secondly, we aimed to account for the fact that unions differ in duration, which might impact the amount of wealth accumulated during the relationship. We also estimated the effects of dissolution depending on the years between the dissolution event and the measurement of post-dissolution wealth. Due to small sample sizes, no statistically significant differences emerged according to the duration of the union and the time since dissolution. Both results are displayed in Online Appendix C and D, respectively.

Finally, we adopted an alternative strategy to estimate how wealth is split between partners after dissolution. Instead of controlling for post-dissolution processes, the wealth rank of individuals was measured based on their per capita wealth before separation and based on individual wealth following separation (i.e. based on legal ownership of wealth). In this manner, post-separation household composition changes, such as the entrance of a new partner, have less of an impact on estimates. Online Appendix E shows how women’s wealth losses following dissolution are greater (and statistically significant) and how gender differences in wealth losses following dissolution from cohabitation become statistically significant under this specification.

\section{DISCUSSION}

In this study, we aimed to contribute to the literature on gender differences in the economic consequences of union dissolution by introducing wealth into the debate. Previous studies on 
the United States showed that divorce is related to considerably lower levels of wealth (Addo \& Lichter, 2013; Painter et al., 2015;), with mixed results regarding gender differences. No previous study examined the dissolution of cohabiting unions. We studied changes in wealth following the dissolution of both cohabiting and married unions in Germany. The general expectation was that union dissolution has larger negative economic consequences in terms of wealth for women as compared to men. This difference was expected to be especially pronounced among formerly cohabiting partners.

The results of our analysis showed that individuals do indeed lose wealth when they dissolve their unions. However, our findings showed that there were no major gender differences in these effects after the dissolution of marriage. Differences were expected to exist in Germany due to the default marital property regime in place, which only prescribes dividing wealth that is accumulated during marriage after divorce. This limited coverage of marital property regimes in Germany might therefore not be as consequential. One possible explanation is that most wealth is accumulated during marriage, and that pre-marriage wealth accounts for a relatively small share of all household wealth divided after dissolution.

We found more support for the expectation that wealth is split differently after the dissolution of cohabiting unions. Even though (formerly) cohabiting men's per capita wealth rank differs little across pre-dissolution and post-dissolution observations, women lose considerably in terms of wealth following the dissolution of a cohabiting union.

Two major limitations of our study have to be addressed in future research before it can be concluded that gender differences in how wealth is split are indeed larger following the dissolution of cohabitation as compared to the dissolution from marriage. Firstly, the imprecision of our estimates requires future corroboration of our findings, as gender differences in estimated wealth losses were only statistically significant in specific 
robustness checks. Secondly, we did not directly collect information on how wealth is split following union dissolution. Instead, we measured per capita wealth at different points in time and employed various strategies to account for other post-separation processes. Even though accounting for such processes in general led to stronger results, directly measuring how wealth is split would be a valuable next step that future research could take.

The indirect measurement of how wealth is split between former partners opens the door to various alternative explanations as to why gender differences in wealth losses are more pronounced following the dissolution of cohabiting unions as compared to the ending of marriages. Cohabiting unions might systematically differ from marriages on characteristics that we did not observe in our study. Most importantly, cohabiting unions might have had a shorter duration than marriages that dissolved and wealth accumulated before union formation will in that case take on a larger share of total household wealth. If wealth brought into a relationship is split less evenly than wealth accumulated during the union (as prescribed for marriages by the standard marital property regime in Germany), this will lead to a less equal splitting of household wealth following the dissolution of cohabiting unions. Even though systematic differences were not observed according to the duration of the union at time of dissolution (Online Appendix D), sample sizes were too small to lead to firm conclusions in that regard. Future research can further investigate whether it are indeed the differences in legal frameworks applying to cohabiting unions and marriages that are responsible for gender differences in wealth losses, and therefore, whether legislation might be a policy option that could address these gender differences.

In conclusion, the results of this paper have shown that how wealth is split following union dissolution might actually amplify rather than lower gender differences in the economic consequences of separations. If cohabitation, but not marriage, is related to gender 
differences in how wealth is split after union dissolution, and if cohabitation is becoming ever more common compared to marriage, union dissolution might become an ever more influential driver of gender differences in wealth. These considerations provoke the question what policy measures might be available to prevent union dissolution from becoming an ever more consequential event for women in particular.

\section{REFERENCES}

Addo, F. R., \& Lichter, D. T. (2013). Marriage, marital history, and black-white wealth differentials among older women. Journal of Marriage and Family, 75(2), 342-362.

Andreß, H. J., Borgloh, B., Bröckel, M., Giesselmann, M., \& Hummelsheim, D. (2006). The economic consequences of partnership dissolution-A comparative analysis of panel studies from Belgium, Germany, Great Britain, Italy, and Sweden. European Sociological Review, 22(5), 533-560.

Di Nallo, A. (2019). Gender Gap in Repartnering: The Role of Parental Status and Custodial Arrangements. Journal of Marriage and Family, 81(1), 59-78.

DiPrete, T. A., \& McManus, P. A. (2000). Family change, employment transitions, and the welfare state: Household income dynamics in the United States and Germany. American Sociological Review, 65(3), 343-370.

Frémeaux, N., \& Leturcq, M. (2018). Prenuptial agreements and matrimonial property regimes in France, 1855-2010. Explorations in Economic History, 68,132-142.

Friedline, T., Masa, R. D., \& Chowa, G. A. (2015). Transforming wealth: Using the inverse hyperbolic sine (IHS) and splines to predict youth's math achievement. Social Science Research, 49, 264-287. 
Halpern-Manners, A., Warren, J. R., Raymo, J. M., \& Nicholson, D. A. (2015) The Impact of Work and Family Life Histories on Economic Well-Being at Older Ages. Social Forces, 93, 1369-1396.

Killewald, A., Pfeffer, F. T., \& Schachner, J. N. (2017). Wealth inequality and accumulation Annual Review of Sociology, 43, 379-404.

Lersch, P. M. (2017). The Marriage Wealth Premium Revisited: Gender Disparities and Within-Individual Changes in Personal Wealth in Germany. Demography, 54(3), 961983.

McManus, P. A., \& DiPrete, T. A. (2001). Losers and winners: The financial consequences of separation and divorce for men. American Sociological Review, 66(2), 246-268.

Painter, M., Frech, A., \& Williams, K. (2015). Nonmarital fertility, union history, and women's wealth. Demography, 52(1), 153-182.

Perelli-Harris, B., \& Sánchez Gassen, N. (2012). How similar are cohabitation and marriage? Legal approaches to cohabitation across Western Europe. Population and Development Review, 38(3), 435-467.

Rainer, H. (2007). Should we write prenuptial contracts? European Economic Review, 51(2), 337-363.

Sierminska, E. M., Frick, J. R., \& Grabka, M. M. (2010). Examining the gender wealth gap. Oxford Economic Papers, 62, 669-690.

Smith, I. (2002). 12 European divorce laws, divorce rates, and their consequences. In: Dnes \& Rowthorn, R (Eds.) The law and economics of marriage and divorce. Cambridge: Cambridge University Press

Smock, P. J. (1994). Gender and the short-run economic consequences of marital disruption. Social forces, 73(1), 243-262. 
Uunk, W. (2004). The economic consequences of divorce for women in the European Union: The impact of welfare state arrangements. European Journal of Population, $20(3), 251-285$.

Van Damme, M., Kalmijn, M., \& Uunk, W. (2008). The employment of separated women in Europe: Individual and institutional determinants. European Sociological Review, 25(2), 183-197.

Vespa, J., \& Painter, M. A. (2011). Cohabitation history, marriage, and wealth accumulation. Demography, 48(3), 983-1004.

Voena, A. (2015). Yours, Mine, and Ours: Do Divorce Laws Affect the Intertemporal Behavior of Married Couples? American Economic Review, 105(8), 2295-2332.

Wilmoth, J., \& Koso, G. (2002). Does marital history matter? Marital status and wealth outcomes among preretirement adults. Journal of Marriage and Family, 64(1), 254268.

Zagorsky, J. L. (2005). Marriage and divorce's impact on wealth. Journal of Sociology, 41(4), 406-424. 


\section{ONLINE APPENDIX}

FIGURE A.1. EFFECT OF SEPARATION ON IHS-TRANSFORMED PER CAPITA WEALTH BY UNION STATUS AND GENDER

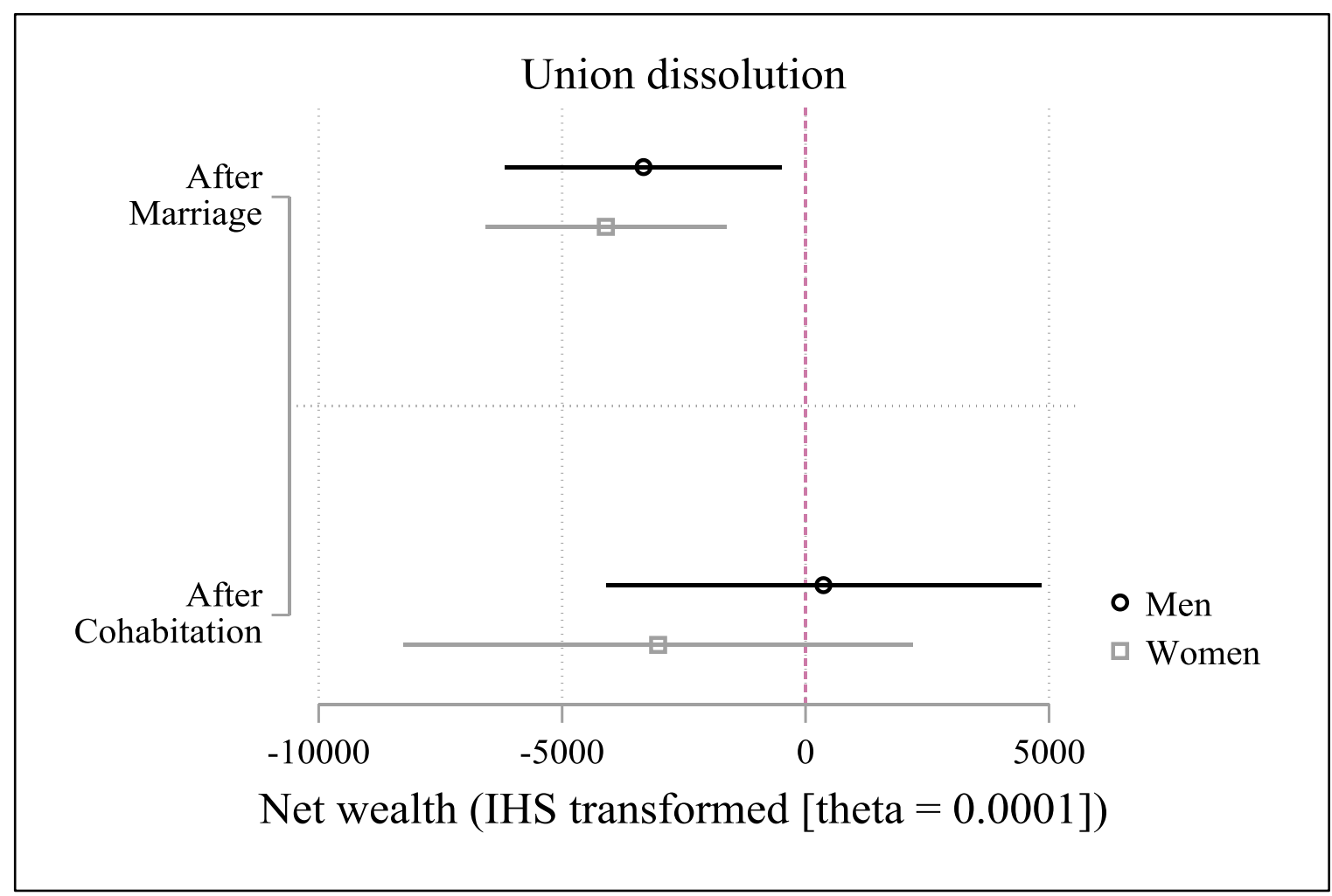

Note: Whiskers indicate $95 \%$ confidence intervals. Coefficients from individual fixed-effects models indicating difference between pre-separation and post-separation wealth. Separate models ran by union status and gender. Replication of Figure 2 using IHS-transformed wealth. 
FiguRE B.1. EFFECT OF LEGAL DIVORCE ON PER CAPITA WEALTH BY GENDER, WITH

\section{AND WITHOUT CONTROLS}

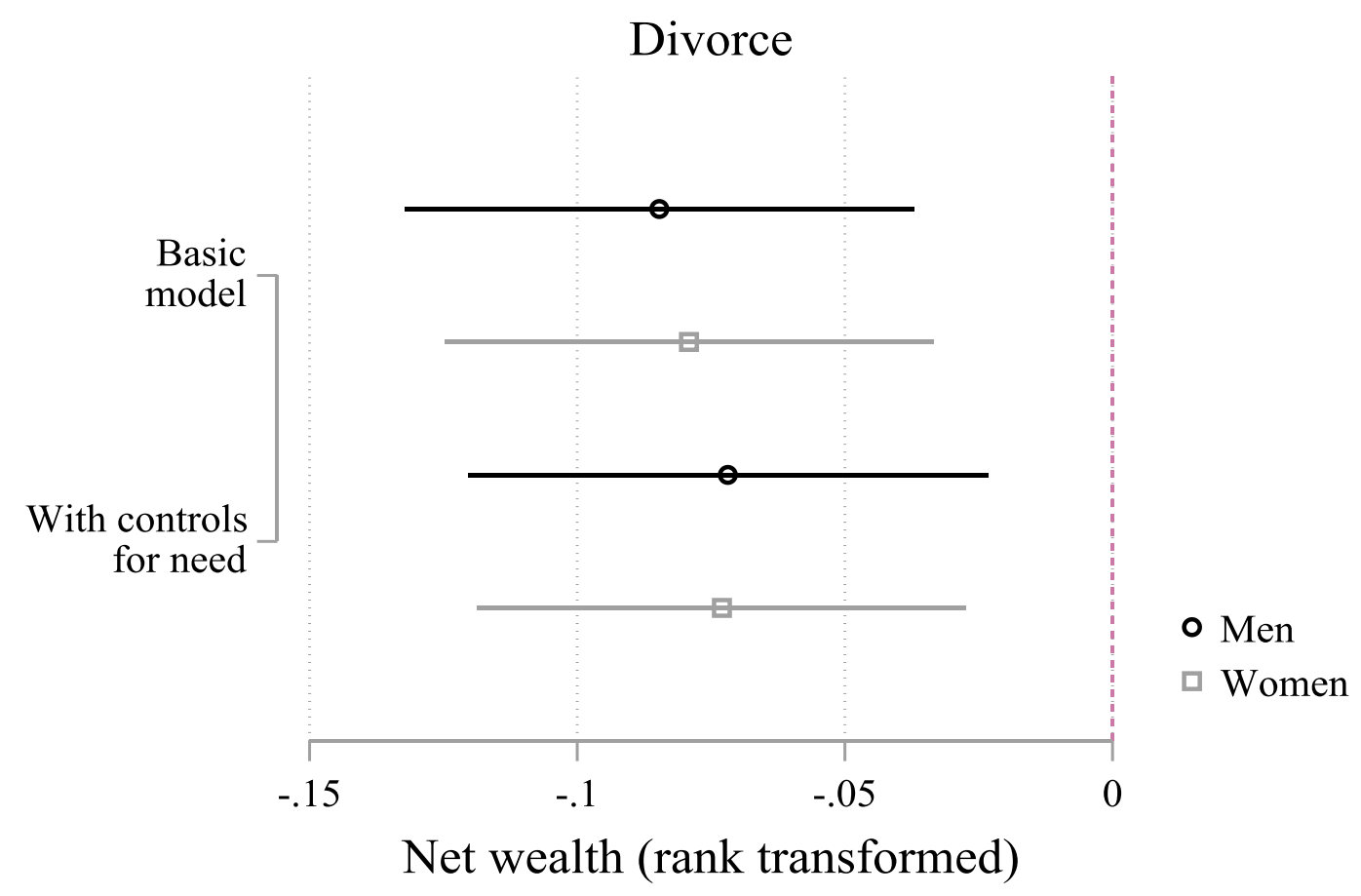

Whiskers indicate 95\% confidence intervals. Coefficients from individual fixed-effects models indicating difference between pre-divorce and post-divorce wealth. Separate models ran by union status and gender. Replication of Figure 2 but taking moment of legal divorce instead of separation as event date. Controlled for employment, presence of (young) children in the household, re-partnering, having moved homes, log household income and self-rated health. 
FIGURE C.1. EFFECT OF SEPARATION ON PER CAPITA WEALTH RANK DEPENDING ON

DURATION OF DISSOLVED RELATIONSHIP, BY UNION STATUS AND GENDER

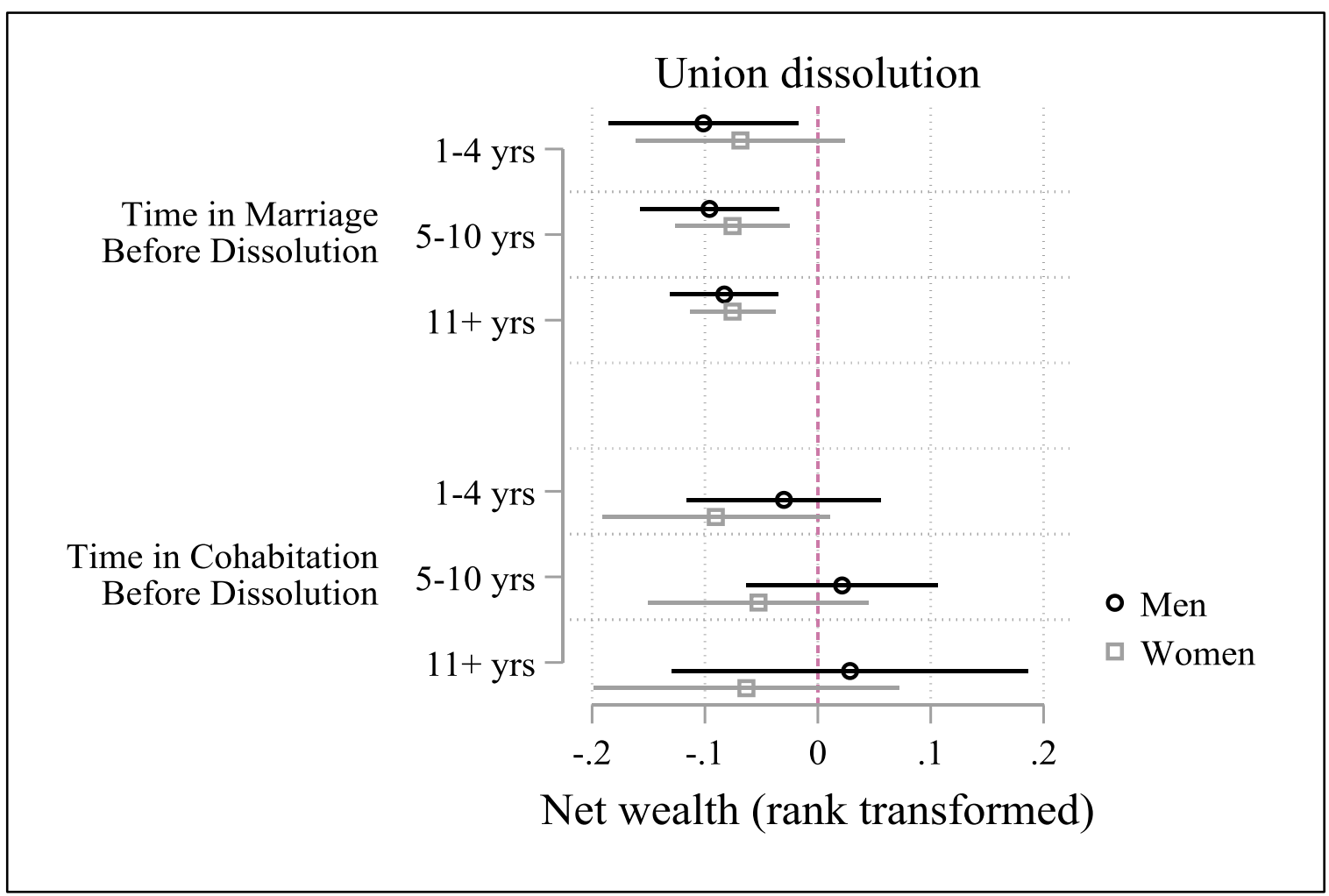

Note: Whiskers indicate $95 \%$ confidence intervals. Coefficients from individual fixed-effects models indicating difference between pre-separation and post-separation wealth. Separate models ran by union status and gender. Separation variable is split according to the duration of the union at the time of union dissolution. 
FIGURE D.1. EFFECT OF SEPARATION FROM MARRIAGE ON PER CAPITA WEALTH RANK

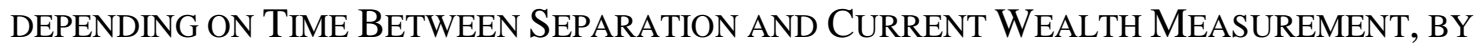

GENDER

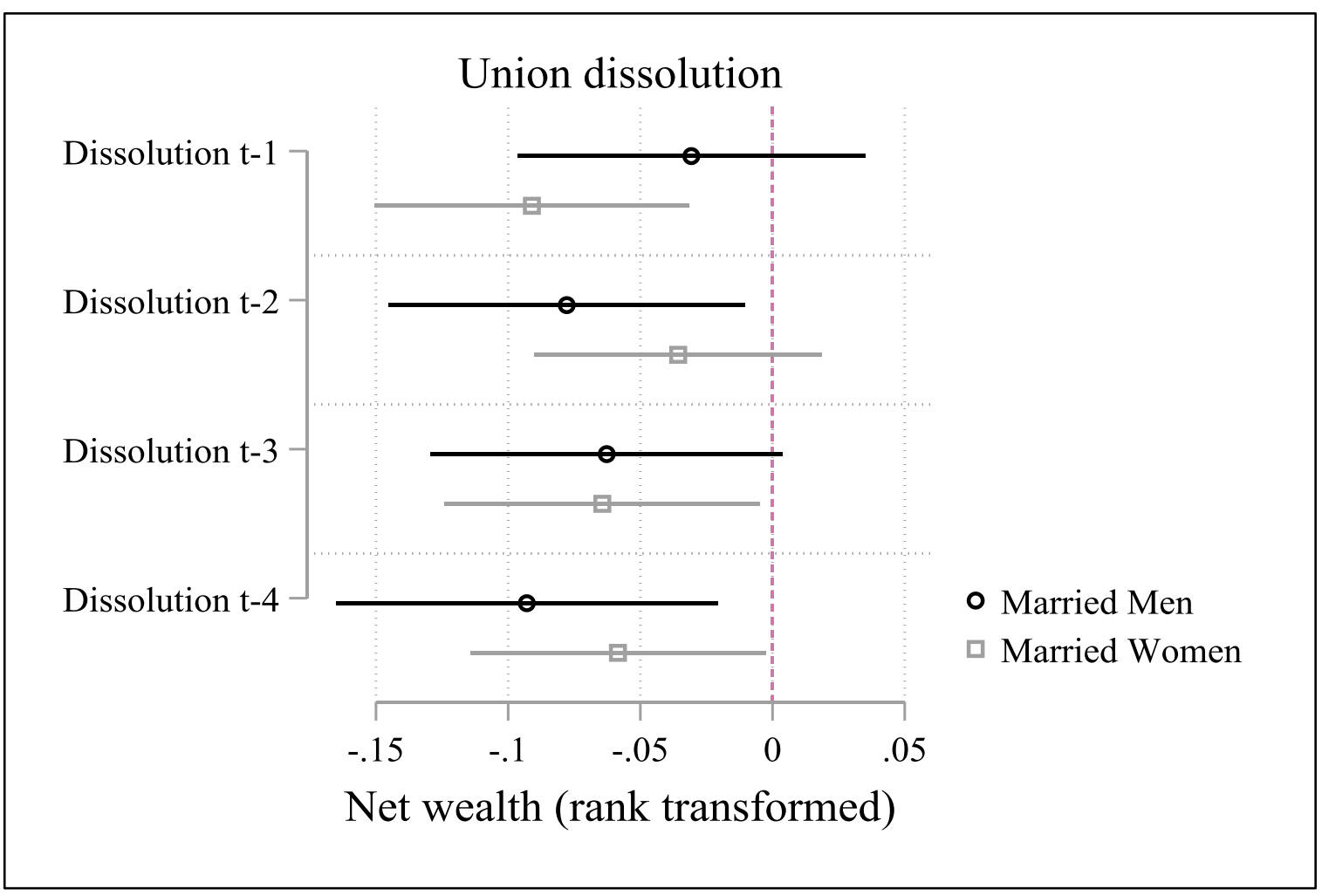

Note: Whiskers indicate $95 \%$ confidence intervals. Coefficients from individual fixed-effects models indicating difference between pre-separation and post-separation wealth. Separate models ran by union status and gender. Separation variable is split according to the time between interview and the wave of reference. 
FIGURE D.2. EFFECT OF SEPARATION FROM COHABITATION ON PER CAPITA WEALTH RANK DEPENDING ON TIME BETWEEN SEPARATION AND CURRENT WEALTH MEASUREMENT, BY GENDER

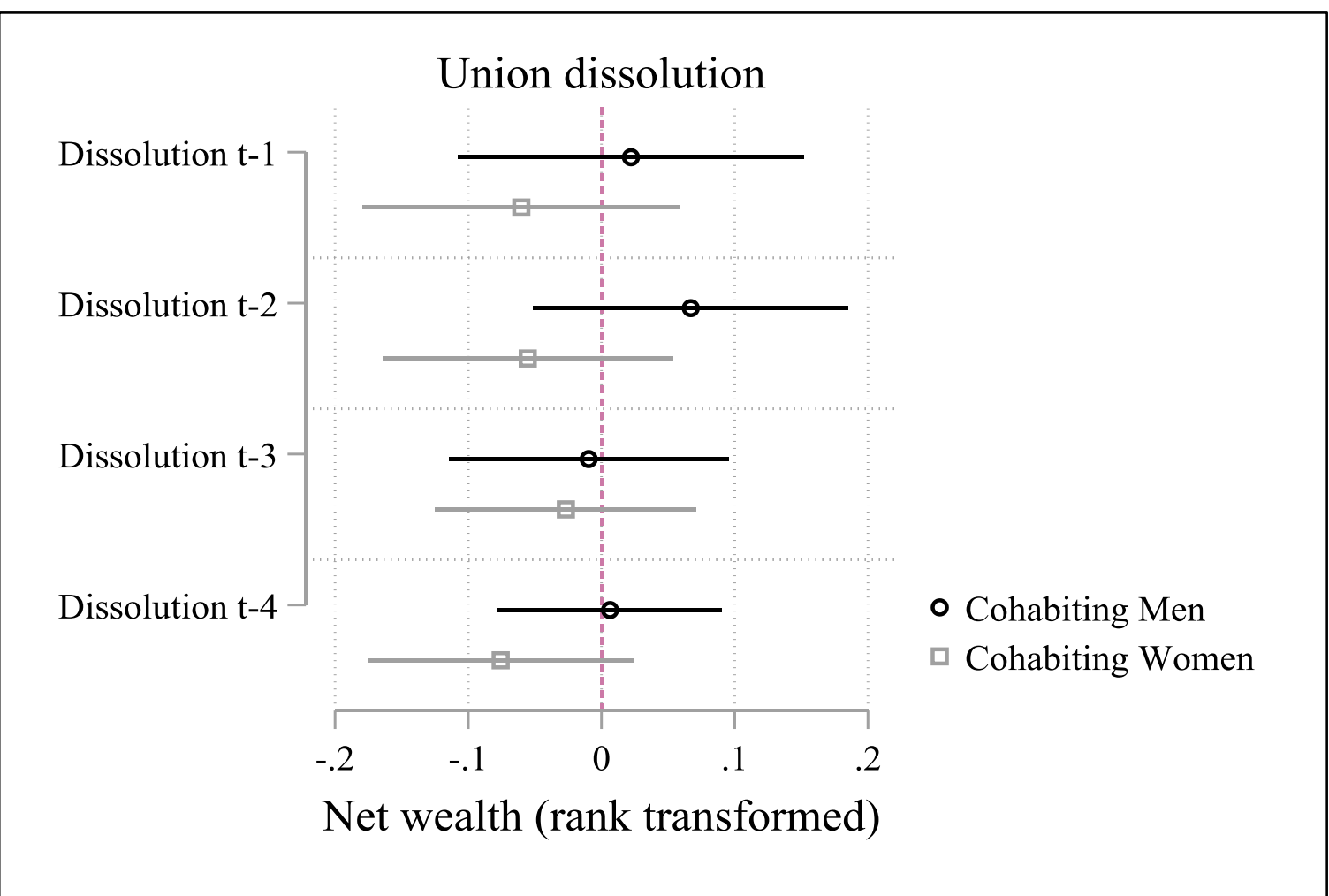

Note: Whiskers indicate 95\% confidence intervals. Coefficients from individual fixed-effects models indicating difference between pre-separation and post-separation wealth. Separate models ran by union status and gender. Separation variable is split according to the time between interview and the wave of reference. 
FIGURE E.1 EFFECT OF SEPARATION ON ‘SPLIT OF WEALTH’, BY UNION STATUS AND GENDER

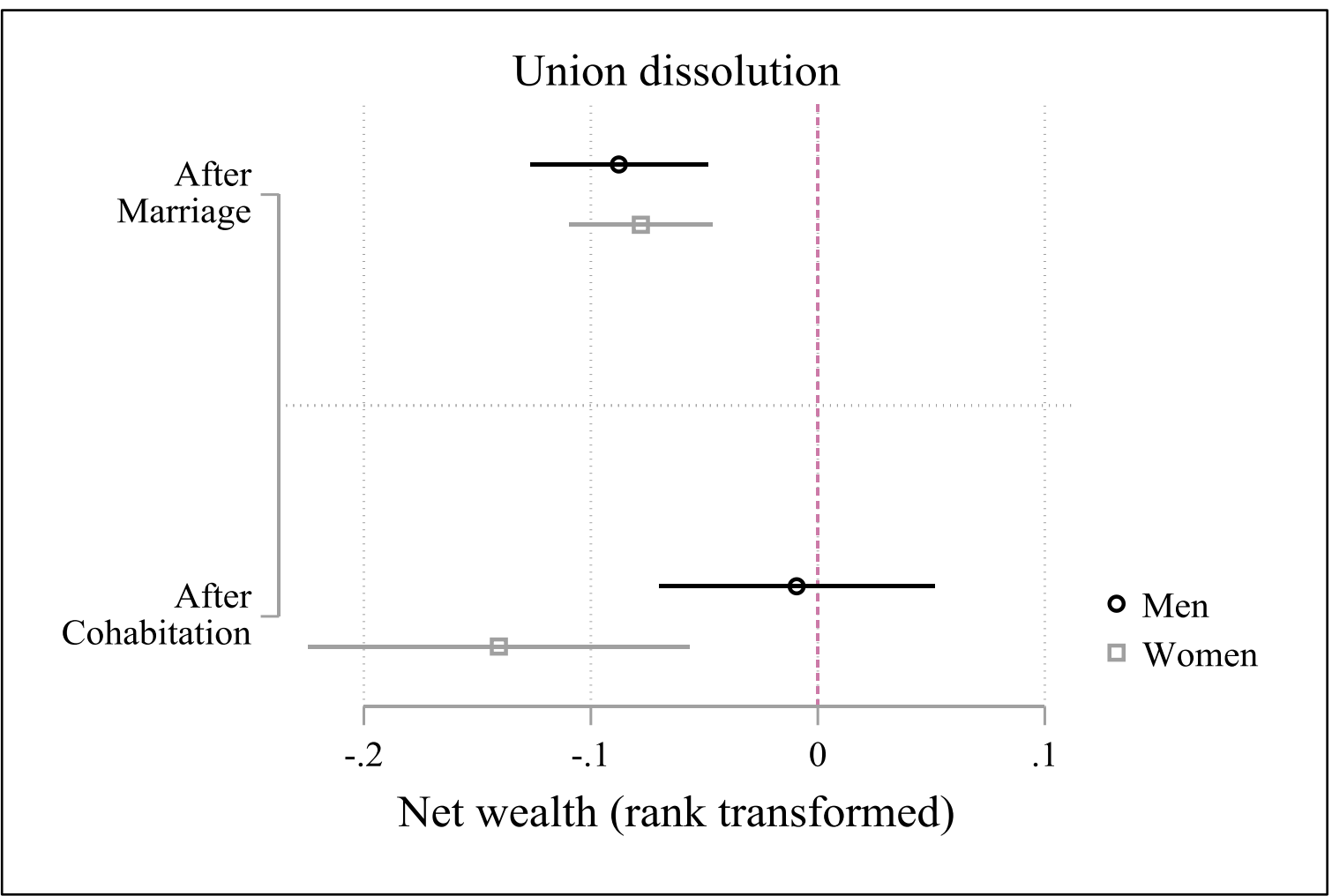

Note: Whiskers indicate 95\% confidence intervals. Coefficients from individual fixed-effects models indicating difference between pre-separation and post-separation wealth. Before separation wealth rank is measured per capita, whereas after separation wealth rank is measured as individual wealth. Separate models ran by union status and gender. Note that due to complications estimating the multiple imputation model, these models exclude cases with missing information on independent variables. 
Table E1. Individual-fixed effects models explaining wealth rank (per capita wealth before separation, individual wealth after separation) by union type.

\begin{tabular}{|c|c|c|}
\hline & $\begin{array}{l}\text { Marriage } \\
\mathrm{B} /(\mathrm{SE})\end{array}$ & $\begin{array}{c}\text { Cohabitation } \\
\mathrm{B} /(\mathrm{SE})\end{array}$ \\
\hline Separation after marriage & $\begin{array}{l}-0.08 * * * \\
(0.02)\end{array}$ & \\
\hline Separation $*$ Women & $\begin{array}{c}0.00 \\
(0.02)\end{array}$ & \\
\hline Separation after cohabitation & & $\begin{array}{l}-0.02 \\
(0.03)\end{array}$ \\
\hline Separation $*$ Women & & $\begin{array}{l}-0.10^{*} \\
(0.04)\end{array}$ \\
\hline Age & $\begin{array}{l}0.02 * * * \\
(0.01)\end{array}$ & $\begin{array}{r}0.02 * \\
(0.01)\end{array}$ \\
\hline Age Squared & $\begin{array}{l}-0.00 * * * \\
(0.00)\end{array}$ & $\begin{array}{l}-0.00 * \\
(0.00)\end{array}$ \\
\hline Wave 1 & $\begin{array}{l}-0.04 * * * \\
(0.04)\end{array}$ & $\begin{array}{l}-0.07 \\
(0.04)\end{array}$ \\
\hline Wave 2 & $\begin{array}{l}-0.04 * * * \\
(0.01)\end{array}$ & $\begin{array}{l}-0.04 * \\
(0.02)\end{array}$ \\
\hline Constant & $\begin{array}{c}0.02 \\
(0.06)\end{array}$ & $\begin{array}{c}0.03 \\
(0.21)\end{array}$ \\
\hline $\begin{array}{l}N \text { (person-years) } \\
\quad \text { (persons) }\end{array}$ & $\begin{array}{r}16,437 \\
5,552\end{array}$ & $\begin{array}{l}990 \\
562\end{array}$ \\
\hline $\begin{array}{r}* \mathrm{p}<.05, * * \mathrm{p}<.01, * * * \mathrm{p}<.001 \\
\text { Note. Before separation we }\end{array}$ & er capita, wh & paration wealth \\
\hline
\end{tabular}

